\title{
Self-Propagating Enabling High Lithium Metal Utilization Ratio Composite Anodes for Lithium Metal Batteries
}

Shaobo Huang ${ }^{1,2+}$, Long Chen ${ }^{2+}$, Tianshuai Wang ${ }^{3}$, Jiangkui Hu ${ }^{l}$, Qianfan Zhang ${ }^{3}$, Hao Zhang ${ }^{2 *}$, Cewen $\mathrm{Nan}^{4 *}$, and Li-Zhen Fan ${ }^{1 *}$

1. Beijing Advanced Innovation Center for Materials Genome Engineering, Beijing Key Laboratory for Advanced Energy Materials and Technologies, University of Science and Technology Beijing, Beijing 100083, China.

2 Beijing Key Laboratory of Advanced Chemical Energy Storage Technologies and Materials Research Institute of Chemical Defense Beijing 100191, China.

3 School of Materials Science and Engineering, Beihang University, Beijing 100191, China.

4 School of Materials Science and Engineering Tsinghua University, Beijing 100084, China.

\section{Corresponding Author}

* E-mail: dr.h.zhang@hotmail.com (Hao Zhang)

* E-mail: fanlizhen@ustb.edu.cn (Li-Zhen Fan)

* E-mail: cwnan@tsinghua.edu.cn (Cewen Nan) 
Content:

1. Experimental section

2. Figures, supplementary text

3. Table

4. Reference 


\section{Experimental Section}

\subsection{Materials preparation}

The commercial Cu-Sn alloy meshes (200 mesh, Daoguan Rubber and Plastic Co, Ltd.) were treatment by ethyl alcohol, diluted hydrochloric acid and deionized water to remove impurities on the surface. Then, the treatment meshes were heated at different temperature in air for $1 \mathrm{~h}$, then cooled down to room temperature. The modified mesh was cut into disks with a diameter of $12.0 \mathrm{~mm}$ and sealed in a vacuum drying oven for the following melt-infusion process.

The Li melt-infusion process was carried out in an argon-filled glove box with less than 1 ppm $\mathrm{O}_{2}$ and $\mathrm{H}_{2} \mathrm{O}$. The Li was previously melted in a stainless-steel case on a hot plate at $250{ }^{\circ} \mathrm{C}$

The composite electrolyte was prepared through a solution casting method. ${ }^{1}$ The nano-sized powders of cubic $\mathrm{Li}_{6.75} \mathrm{La}_{3} \mathrm{Zr}_{1.75} \mathrm{Ta}_{0.25} \mathrm{O}_{12}$ (LLZTO) were synthesized through conventional solid-state reaction according to previous work. ${ }^{2}$ A mixing solution was prepared by dropped Lithium bis(trifluoromethanesulphonyl)imide (LITFSI, 99.99\%, Sigma-Aldrich) powers and poly(vinylidene fluoride) (PVDF, Arkema) with a mass ration of 2:1 in a $10 \%$ solution $\mathrm{N}$-methyl pyrrolidone for intense stirring for $6 \mathrm{~h}$ at room temperature. Then, LLZTO was added into the above solution with $50 \mathrm{wt} . \%$ in the total amount of PVDF and LLZTO. Finally, the mixture solution was poured onto polyimide (PI, Jiangxi Advanced Nanofiber S\&T Co., Ltd) film, and heated under vacuum condition for $12 \mathrm{~h}$ at $80{ }^{\circ} \mathrm{C}$ to achieve the PI-LLZTO-PVDF composite solid electrolyte ( $\sim 20 \mu \mathrm{m}$ in thickness). 


\subsection{Structural characterization}

SEM images and EDS mapping were operated at $10 \mathrm{kV}$ on a FEG650 microscope. XRD patterns were recorded on a Bruker D8 Advance diffractometer equipped with a $\mathrm{Cu}$-Ka radiation source. TEM images were performed on a FEI Tec G2F30. XPS spectra were recorded by ESCALAB 250Xi (Thermo Fisher) to analyze the surface chemistry of the electrodes.

\subsection{Electrochemical characterization}

All batteries were assembled with standard CR2025 coin-type batteries. A Cu-Li composite electrode or bare $\mathrm{Li}$ foil were employed as the working and counter electrodes in symmetrical batteries, respectively. To fabricate the cathode electrodes for full battery testing, the active materials of $\mathrm{LiNi}_{0.5} \mathrm{Co}_{0.3} \mathrm{Mn}_{0.2} \mathrm{O}_{2}(\mathrm{NCM}$, by Tianjiao Corp. China) were achieved by mixed with acetylene black and PVDF at a weight ratio of 8:1:1 with N-methyl-2-pyrrolidone as the solvent. The areal mass loading of cathode is about $3.5 \mathrm{mg} \mathrm{cm}^{-2}$. For the liquid full battery, Celgard 2400 was utilized as the separator, and the electrolyte was composed of 1M LiTFSI in 1,3-dioxolane (DOL)/1,2dimethoxyethane (DME) $(1.0 \mathrm{M} ; \mathrm{v} / \mathrm{v}=1: 1)$ with $1 \% \mathrm{LiNO}_{3}$ as additive (Dodo Chem). For the solid-state full battery, which was composed of NCM cathode, composite electrolyte and Li anode. The interface between cathode and solid electrolyte was added 3-4.0 $\mu \mathrm{L}$ liquid electrolyte to improve the interface contact. ${ }^{3-5}$ EIS were carried out on a Solartron 1470E electrochemical workstation from $100.0 \mathrm{kHz}$ to $0.1 \mathrm{~Hz}$. Galvanostatic cycling was performed on a standard eight-channel battery tester (CT2001A, Wuhan LAND Electronics Co, Ltd.) at room temperature. The $\mathrm{Li}^{+}$ 
transference number $\left(t_{+}\right)$of composite electrolytes was tested with direct current polarization in symmetric cell. The calculated of $t_{+}$is based on the following equation (1):

$$
t_{+}=\frac{I_{s}\left(\Delta \mathrm{V}-I_{o} R_{1}^{0}\right)}{I_{o}\left(\Delta \mathrm{V}-I_{S} R_{1}^{S}\right)}
$$

Where $I_{o}$ and $I_{S}$ are the initial and steady currents, respectively. $R_{1}^{\mathrm{o}}$ and $R_{1}^{\mathrm{s}}$ are the charge-transfer resistances of $\mathrm{Li}$ symmetric cell before and after polarization. $\quad \Delta \mathrm{V}$ is a polarization voltage at $10 \mathrm{mV}$.

\subsection{First principles calculations}

First principles calculations were performed using the Vienna ab initio simulation package (VASP) in the framework of density functional theory (DFT) with projector augmented wave pseudopotentials. The Pardew-Burke-Ernzerhof (PBE) functional was adopted to describe the exchange-correlation function based on the generalized gradient approximation (GGA). The energy cutoff for plane wave basis was set to $500 \mathrm{eV}$ in conjunction with the Gamma-centered Monkhorst-Pack scheme for k-point sampling. The convergence criterion of the total energy was set to $10^{-6} \mathrm{eV}$. A Gaussian smearing of $0.05 \mathrm{eV}$ was adopted for the electronic temperature to speed up the calculation convergence. For geometric optimizations, all ions were relaxed to a force tolerance less than $0.01 \mathrm{eV} / \AA$. The pictorial representations of the structures and electronic image were prepared using the Visualization for Electronic and Structural Analysis (VESTA). 
2. Figures, supplementary text

(a)

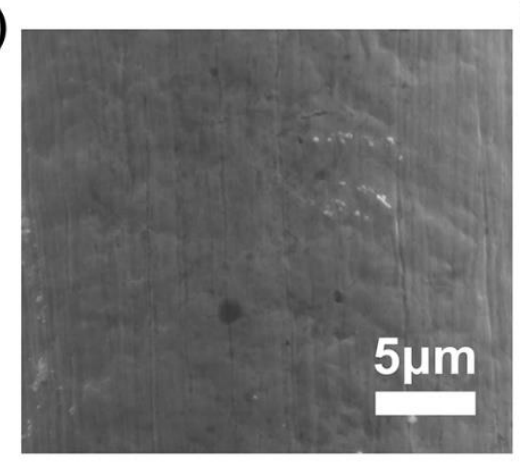

(c)

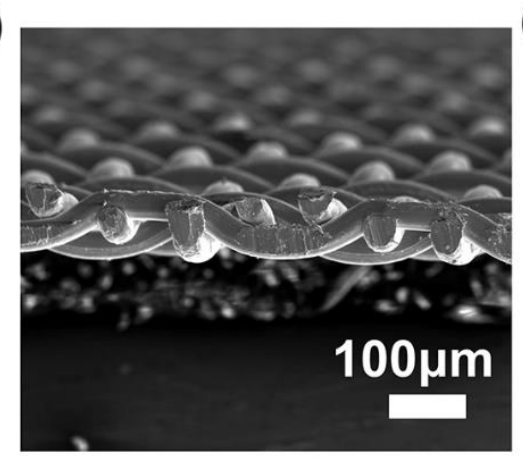

(b)

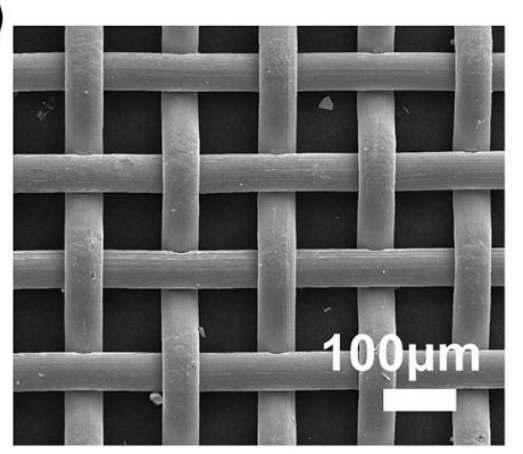

(d)

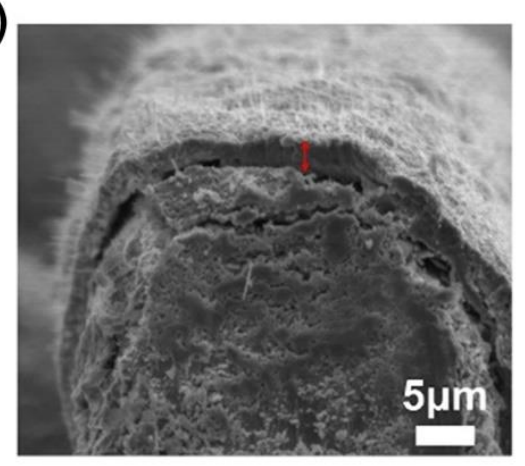

Figure S1. SEM images of mesh before and after heat treatment. (a) High magnification.

(b) Low magnification. (c) Side-section. (d) The side-section image after heat treatment. 


\section{$\mathrm{SnO}_{2} 0.74 \mathrm{eV}$}

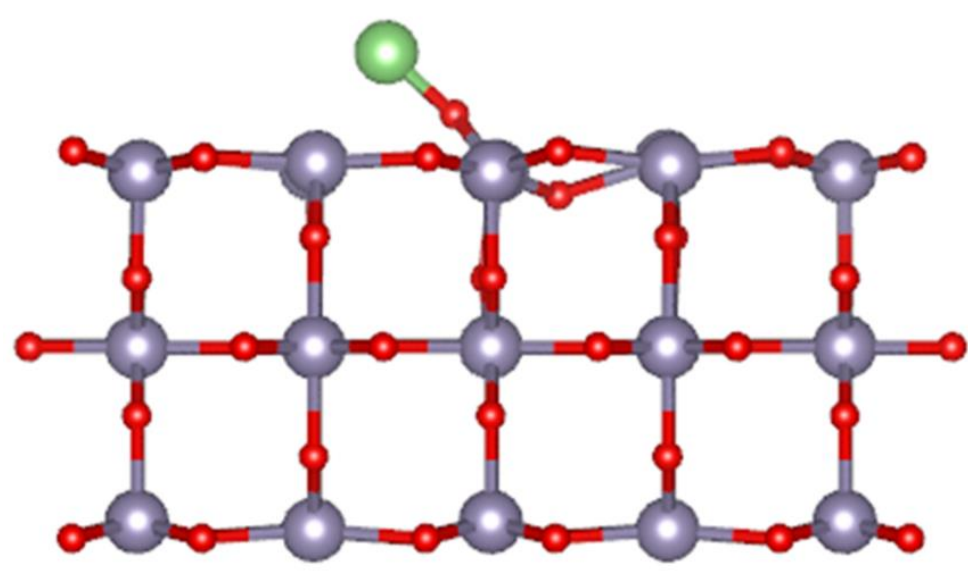

* Sn $\bigcirc$ Li

Figure S2. The preferred adsorption structures and adsorption energies of a single Li on tin oxide $(0.74 \mathrm{eV})$. 

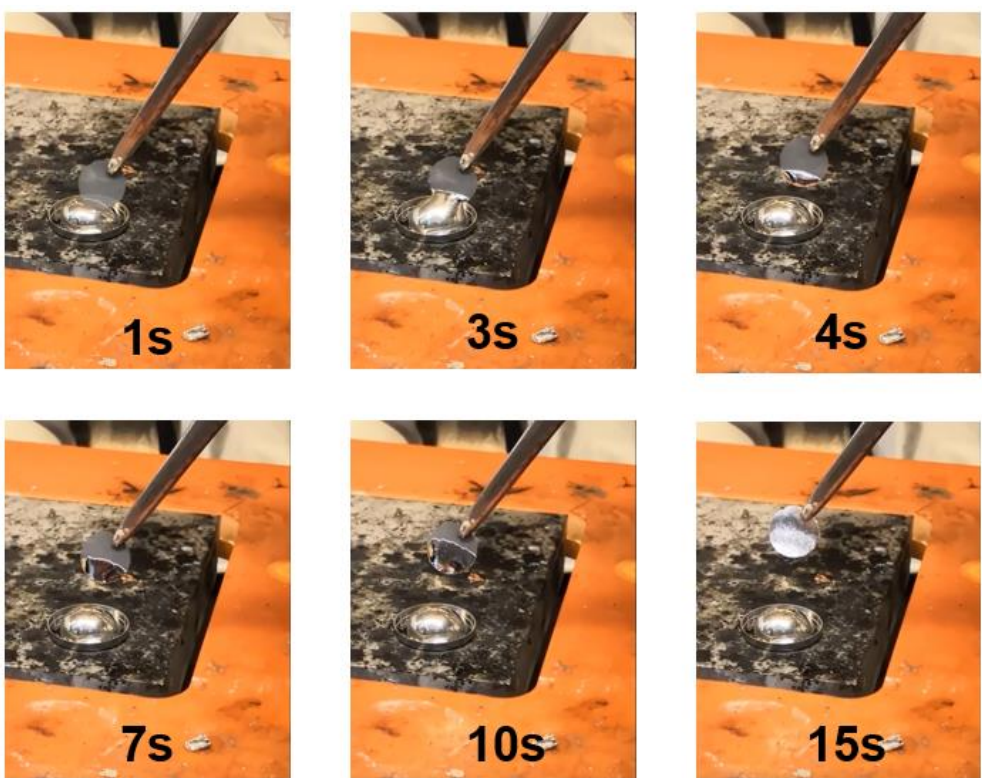

Figure S3. The optical photos of self-propagating process with different time. 


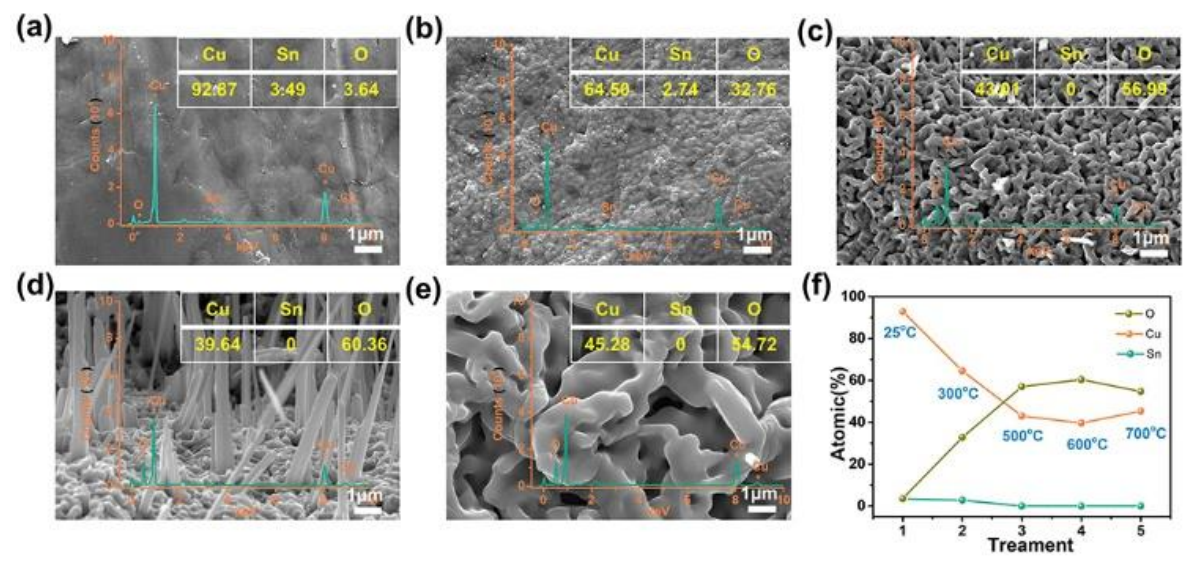

Figure S4. SEM images and EDS under different heat temperature. (a) pristine $\mathrm{Cu}-\mathrm{Sn}$ mesh. (b) $300^{\circ} \mathrm{C}$. (c) $500^{\circ} \mathrm{C}$. (d) $600^{\circ} \mathrm{C}$. (e) $700^{\circ} \mathrm{C}$. (g) Atomic percent of Cu, Sn and $\mathrm{O}$. 

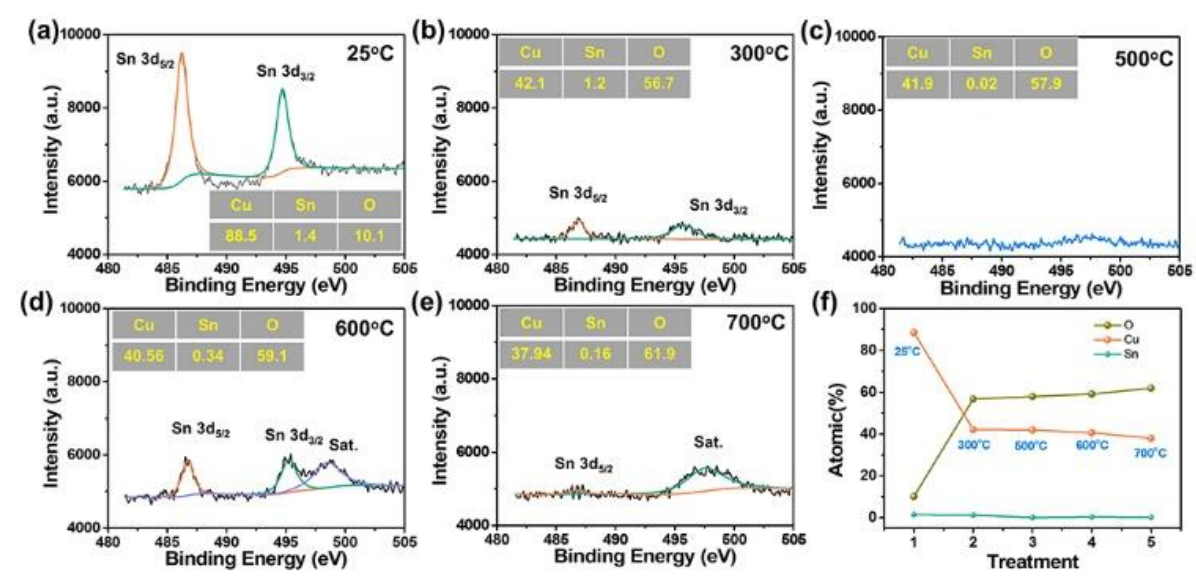

Figure S5. XPS curves of Sn under different heat temperature. (a) pristine $\mathrm{Cu}-\mathrm{Sn}$ mesh.

(b) $300^{\circ} \mathrm{C}$. (c) $500^{\circ} \mathrm{C}$. (d) $600^{\circ} \mathrm{C}$. (e) $700^{\circ} \mathrm{C}$. (g) Atomic percent of Cu, Sn and O.

SEM, EDS and XPS are used to detect the content of Sn in the pristine and treated $\mathrm{Cu}-\mathrm{Sn}$ alloy. For the pristine $\mathrm{Cu}-\mathrm{Sn}$ alloy mesh, the content of $\mathrm{Sn}$ is below 5\% (Figure S4). After heat treatment, the $\mathrm{Cu}$ and $\mathrm{Sn}$ elements will be oxidized, and no peak of Sn, can be detected (Figure S4b-e). Similarly, the XPS results also demonstrates that the atomic percent of $\mathrm{Sn}$ is just $0.02 \%$ at $500^{\circ} \mathrm{C}$ (Figure S5). After heat treatment, the peak of $\mathrm{Sn}$ can be almost negligible. Thus, due to the minuscule amount of $\mathrm{Sn}$ atom in $\mathrm{Cu}$ Sn alloy, the stannic oxide couldn't be detected. Meanwhile, the oxide layer (copper oxide or stannic oxide) is just acted as lithiophilic layer to facilitate the subsequent selfpropagating process. The released chemical energy from redox reaction between $\mathrm{Li}$ and lithiophilic layer is strong enough to realize the Li covers and spreads evenly over the 3D mesh surface. Consequently, the $\mathrm{Sn}$ or $\mathrm{SnO}_{2}$ has litter effect on the subsequent testing. 


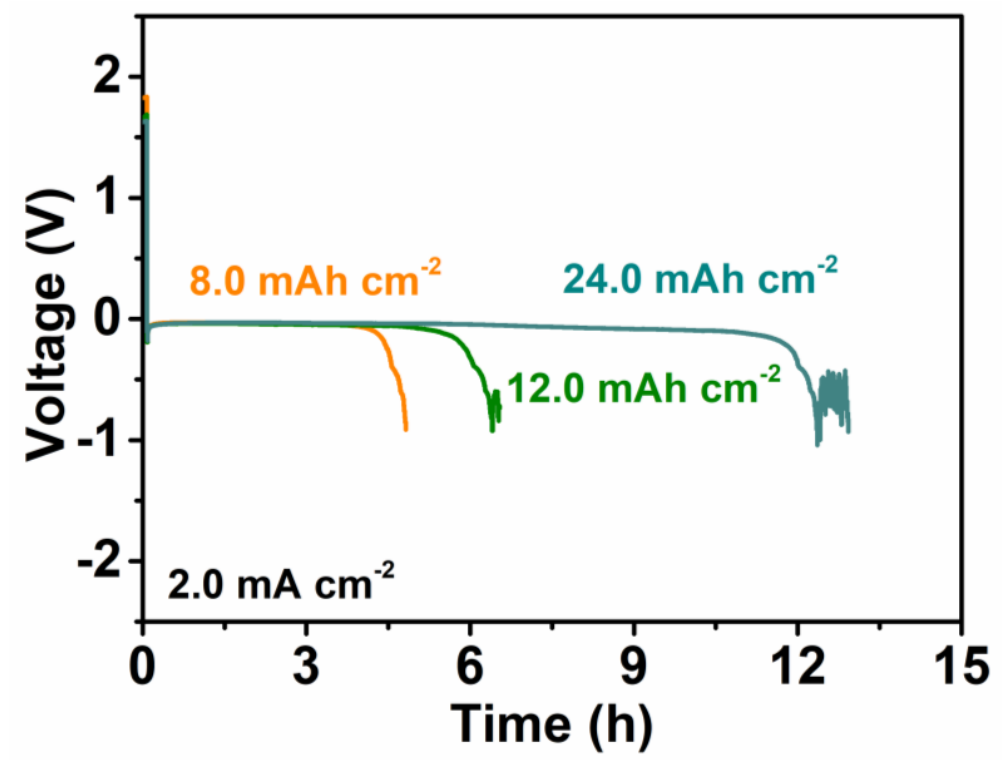

Figure S6. The discharge curves of composite $\mathrm{Cu} / \mathrm{Li}$ anode at current density of 2.0 $\mathrm{mA} \mathrm{cm}{ }^{-2}$. 
(a)

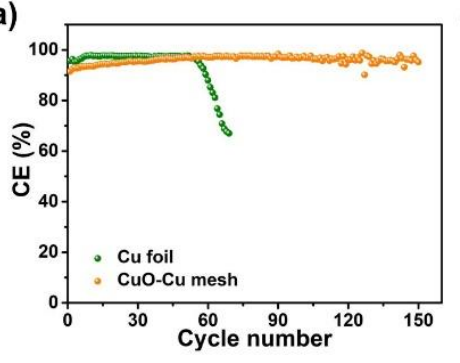

(b)

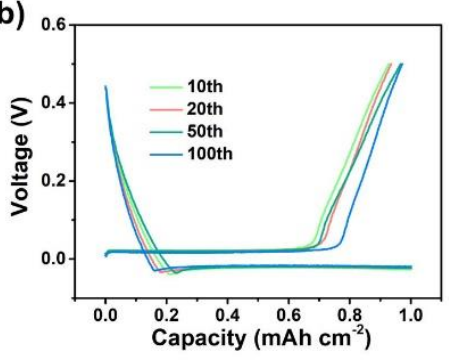

(c)

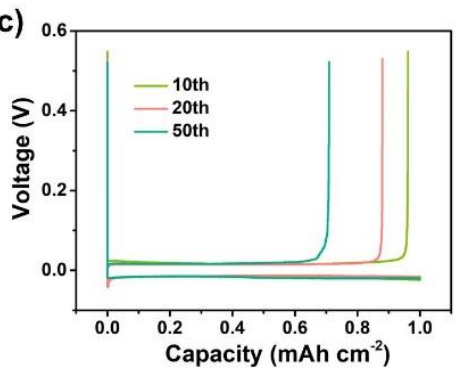

Figure S7. Electrochemical tests in half batteries, while $\mathrm{Li}$ foil as anode and $\mathrm{Cu}$ foil or

CuO-Cu mesh as cathode. (a) Coulombic efficiencies. (b) The charge/charge curves of CuO-Cu mesh. (c) The charge/discharge curves of copper foil. 

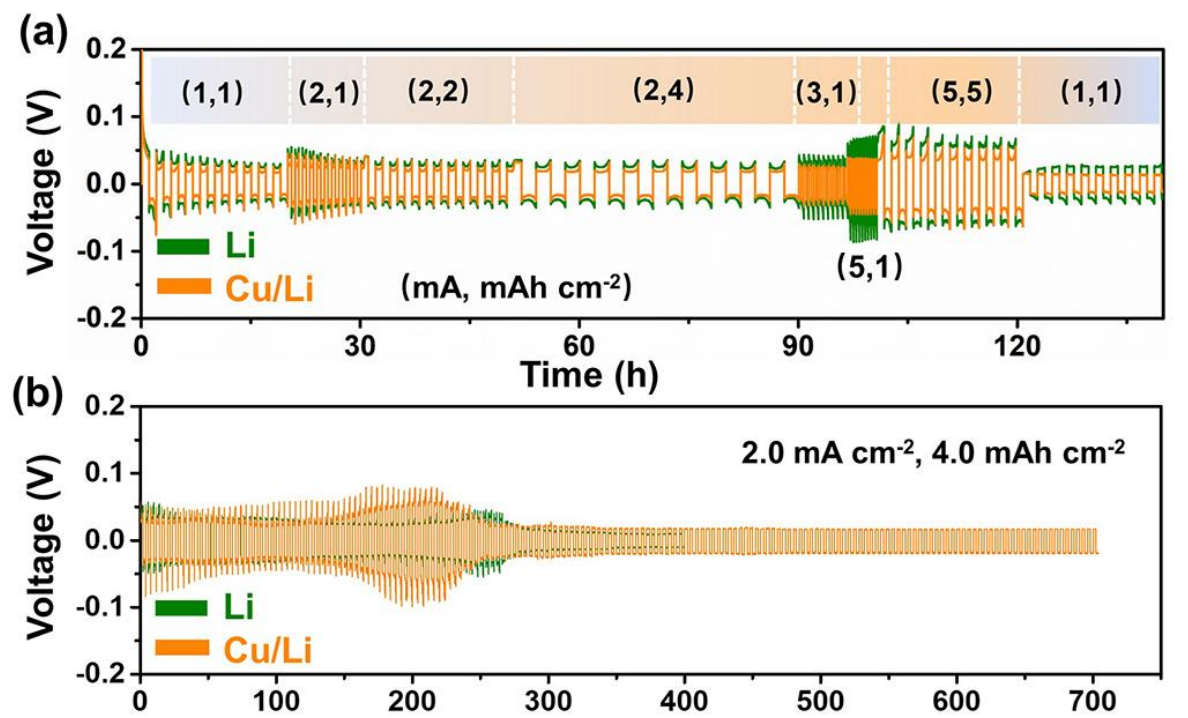

(c)

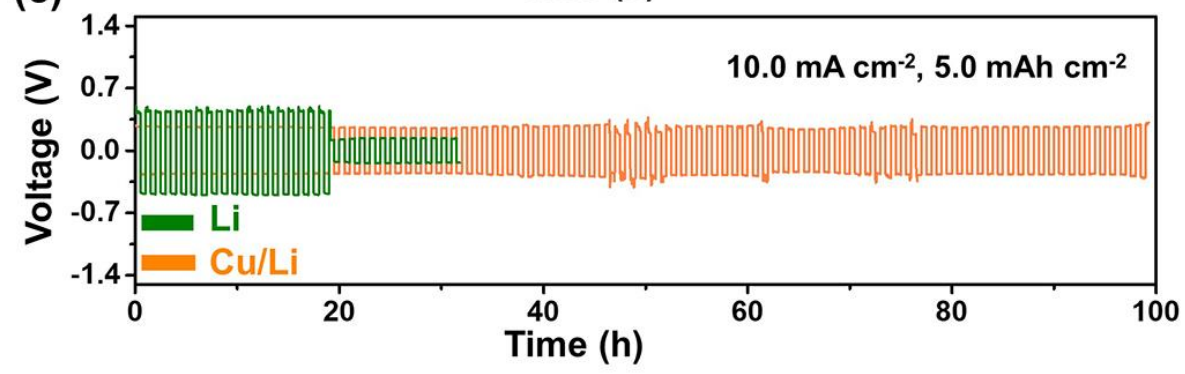

Figure S8. Voltage profiles of bare $\mathrm{Li}$ and $\mathrm{Cu} / \mathrm{Li}$ symmetric batteries at critical density and capacity. (a) Rate performance. (b) Cycling performance at $2.0 \mathrm{~mA} \mathrm{~cm}{ }^{-2}$ with a capacity of $4.0 \mathrm{mAh} \mathrm{cm}^{-2} \mathrm{Li}$. (c) Cycling performance at $10.0 \mathrm{~mA} \mathrm{~cm}^{-2}$ with a capacity of $5.0 \mathrm{mAh} \mathrm{cm}^{-2} \mathrm{Li}$. 

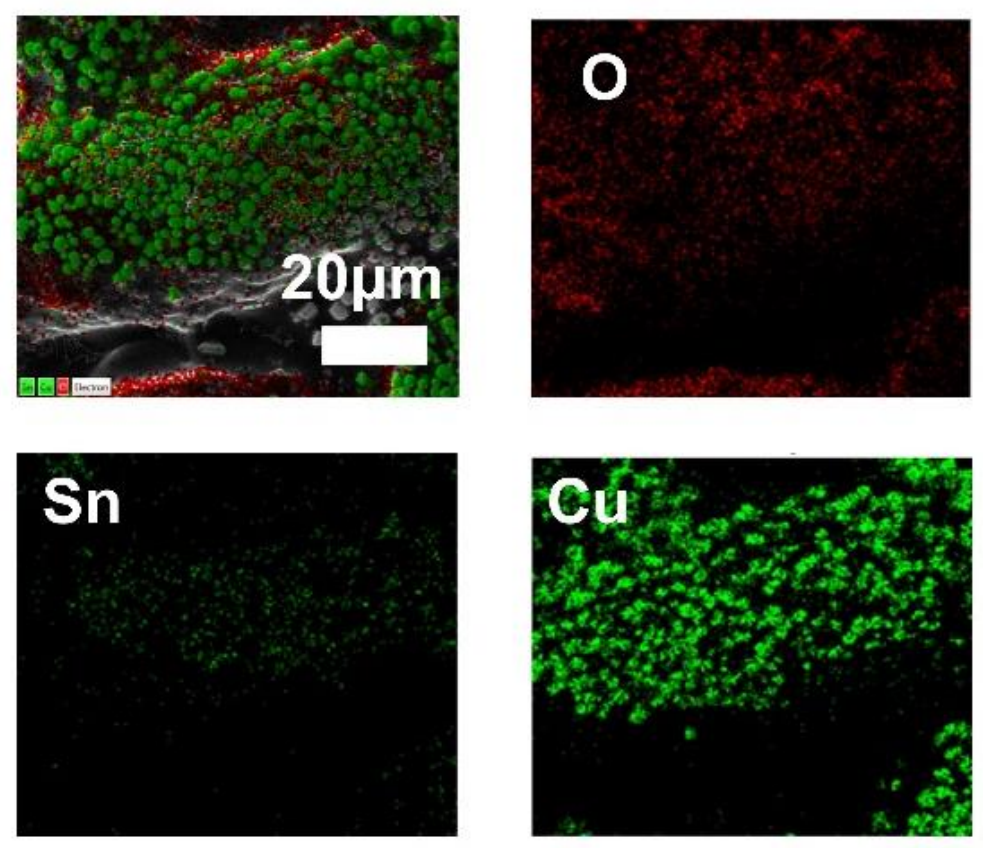

Figure S9. The surface mapping results of metal mesh after molten-infusion process. 


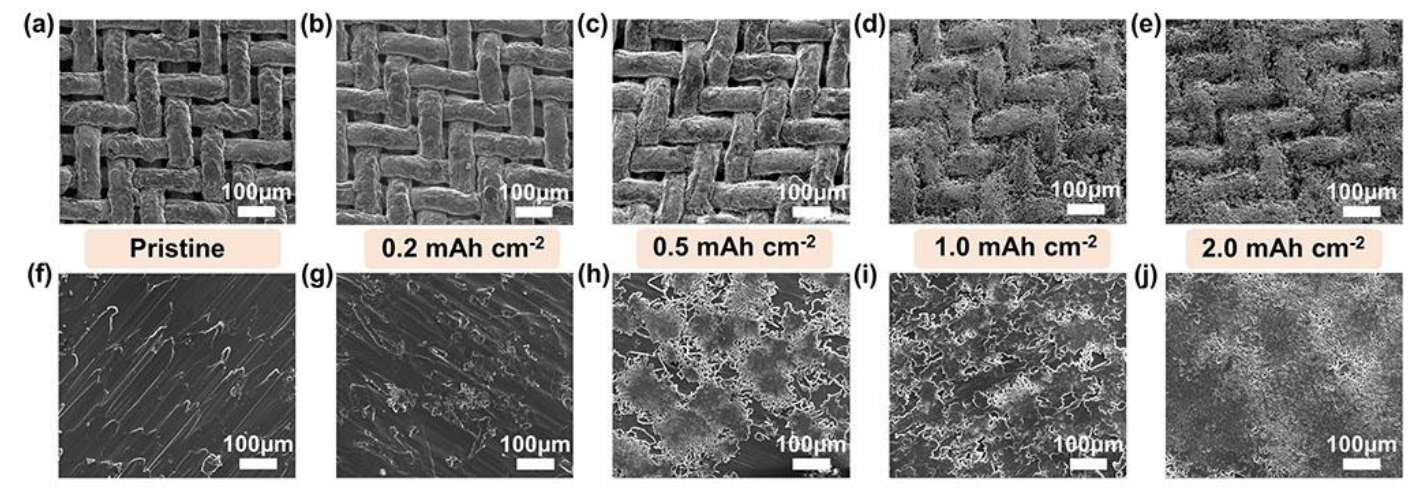

Figure S10. Morphology evolution of the $\mathrm{Cu} / \mathrm{Li}$ and bare $\mathrm{Li}$ foil electrodes with different Li plating. For $\mathrm{Cu} / \mathrm{Li}$ anode: (a) Pristine, (b) $0.2 \mathrm{mAh} \mathrm{cm}^{-2}$, (c) $0.5 \mathrm{mAh} \mathrm{cm}^{-2}$. (d) $1.0 \mathrm{mAh} \mathrm{cm}^{-2}$. (e) $2.0 \mathrm{mAh} \mathrm{cm}^{-2}$. For bare Li anode: (a) Pristine, (b) $0.2 \mathrm{mAh} \mathrm{cm}^{-2}$, (c) $0.5 \mathrm{mAh} \mathrm{cm}^{-2}$. (d) $1.0 \mathrm{mAh} \mathrm{cm}^{-2}$. (e) $2.0 \mathrm{mAh} \mathrm{cm}^{-2}$. 

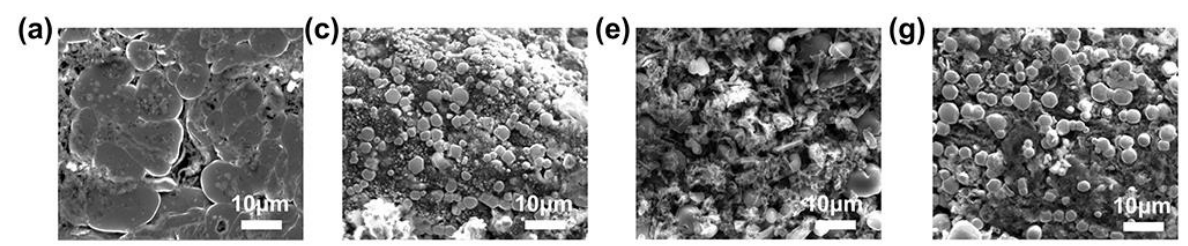

(b)
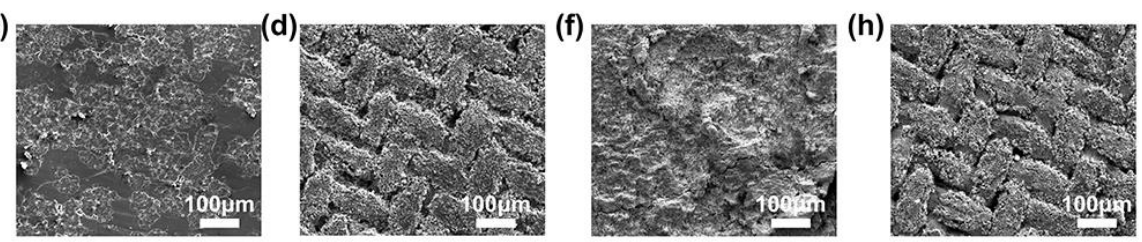

Figure S11. Top-section morphology evaluation of bare $\mathrm{Li}$ or $\mathrm{Cu} / \mathrm{Li}$ symmetric batteries after cycling at $1.0 \mathrm{~mA} \mathrm{~cm}{ }^{-2}$ with a capacity of $1.0 \mathrm{mAh} \mathrm{cm}^{-2}$. (a-b) Bare Li after 5 cycles. (c-d) $\mathrm{Cu} / \mathrm{Li}$ anode after 5 cycles. (e-f) Bare Li after 100 cycles. (g-h) $\mathrm{Cu} / \mathrm{Li}$ anode after 100 cycles. 
(a)

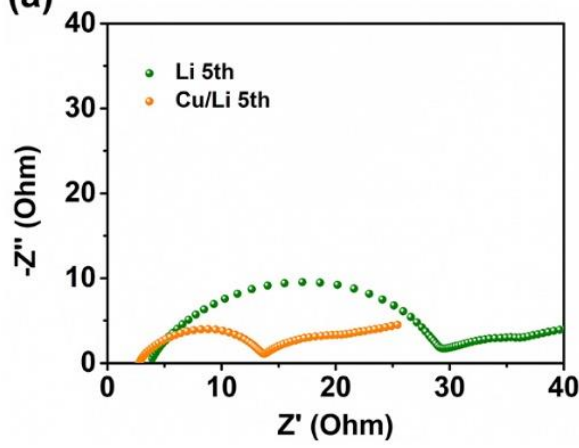

(b)

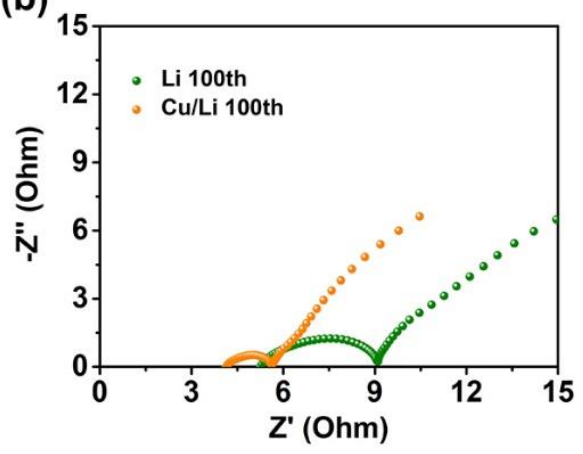

Figure S12. Nyquist plots of the symmetric batteries using bare $\mathrm{Li}$ and composite $\mathrm{Cu} / \mathrm{Li}$ at a current density of $1.0 \mathrm{~mA} \mathrm{~cm}{ }^{-2}$ with a capacity of $1.0 \mathrm{mAh} \mathrm{cm}^{-2}$. (a) 5 cycles. (b) 100 cycles. 

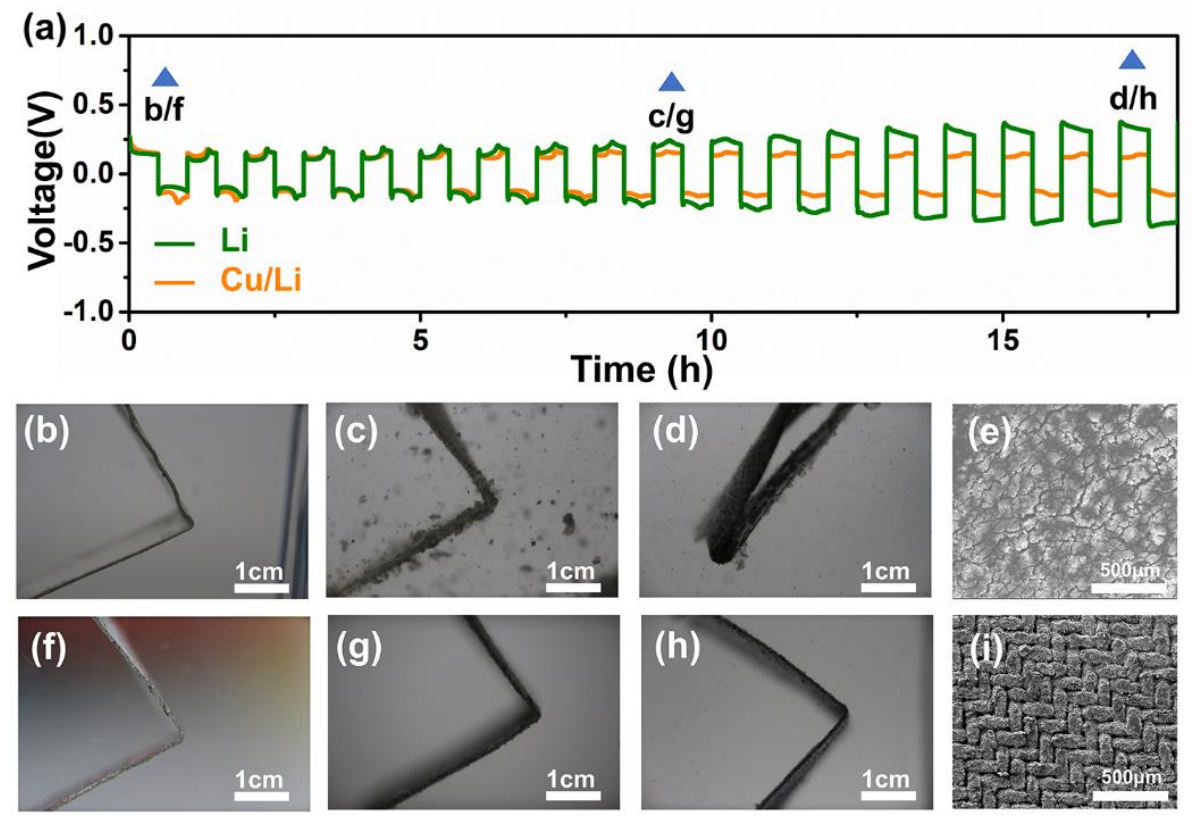

Figure S13. Bending experiments at a bending angle of $90^{\circ}$. (a) Galvanostatic cycling performances. For Li foil, (b) Optical image of original electrode. (c) Optical image of after 10 cycles. (d) Optical image after 18 cycles. (e) SEM image after 10 cycles. For $\mathrm{Cu} / \mathrm{Li}$ anode, (f) Optical image of original electrode. (g) Optical image after 10 cycles. (h) Optical image after 18 cycles. (i) SEM images after 18 cycles. (b) Original optical images.

For the bare Li foil at bending $90^{\circ}$, some particles float in the electrolyte after 10 cycles, which indicates the generation of by-products during the chare/discharge process (Figure S13b-c). After 18 cycles, the electrodes deform and fold together, indicating the uneven Li stripping/depositing electrochemical behavior at the bend region. SEM image of the bare Li foil after 18 cycle reveals some Li dendrites laying on the surface (Figure $\mathrm{S} 13 \mathrm{~d}-\mathrm{e})$. In contrast, the $\mathrm{Cu} / \mathrm{Li}$ electrode delivers a stable structural with no obvious by-products floating in the electrolyte after 18 cycles. The SEM image also reveals similar results with a flat surface and no Li dendritic growth (Figure S13f-i). 

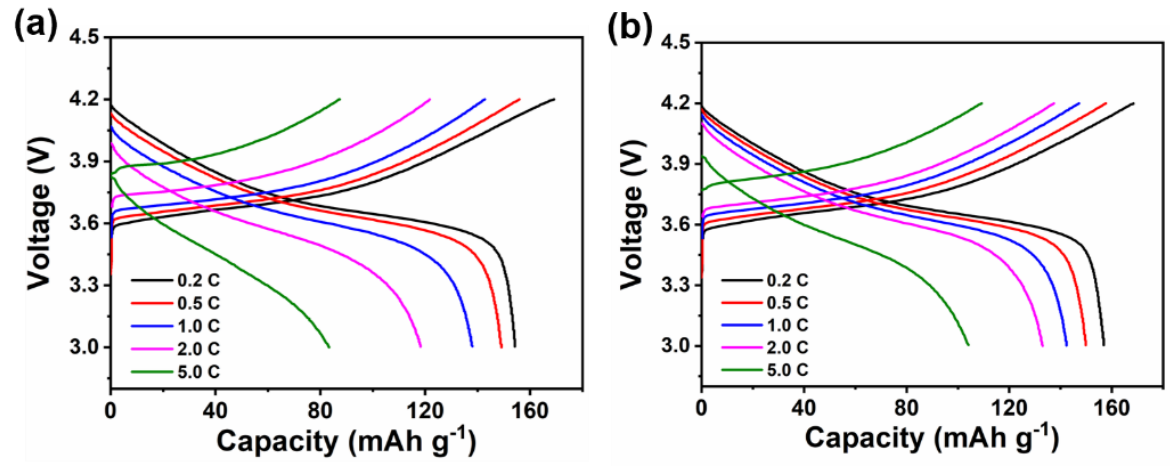

Figure S14. Rate performance of $\mathrm{Li}$ or $\mathrm{Cu} / \mathrm{Li}|| \mathrm{NCM}$ full cells in liquid electrolyte. 

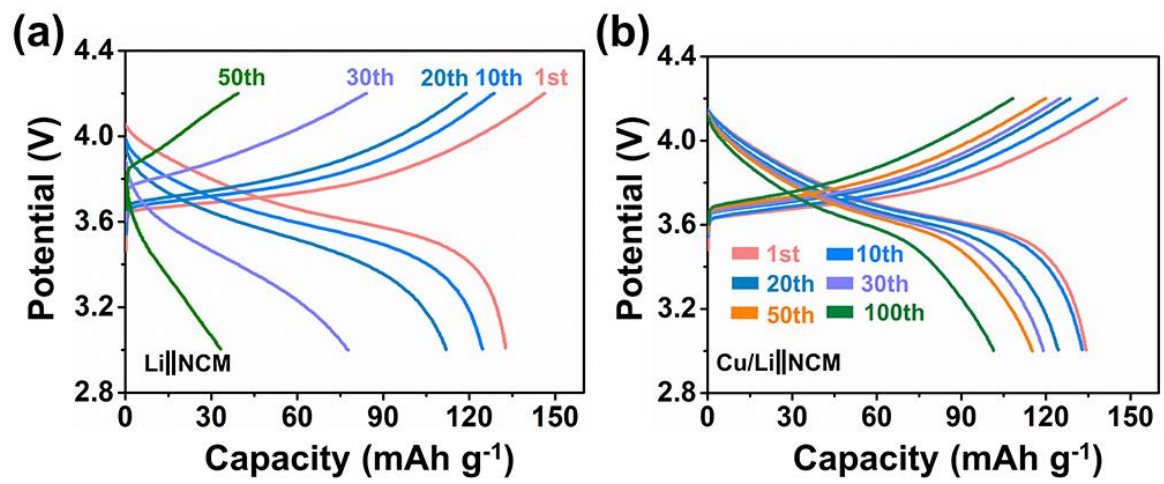

Figure S15. Typical charge-discharge voltage profiles of (a) $\mathrm{Li} \| \mathrm{NCM}$ and (b) $\mathrm{Cu} / \mathrm{Li} \| \mathrm{NCM}$ full batteries in liquid electrolyte at $1.0 \mathrm{C}$. 

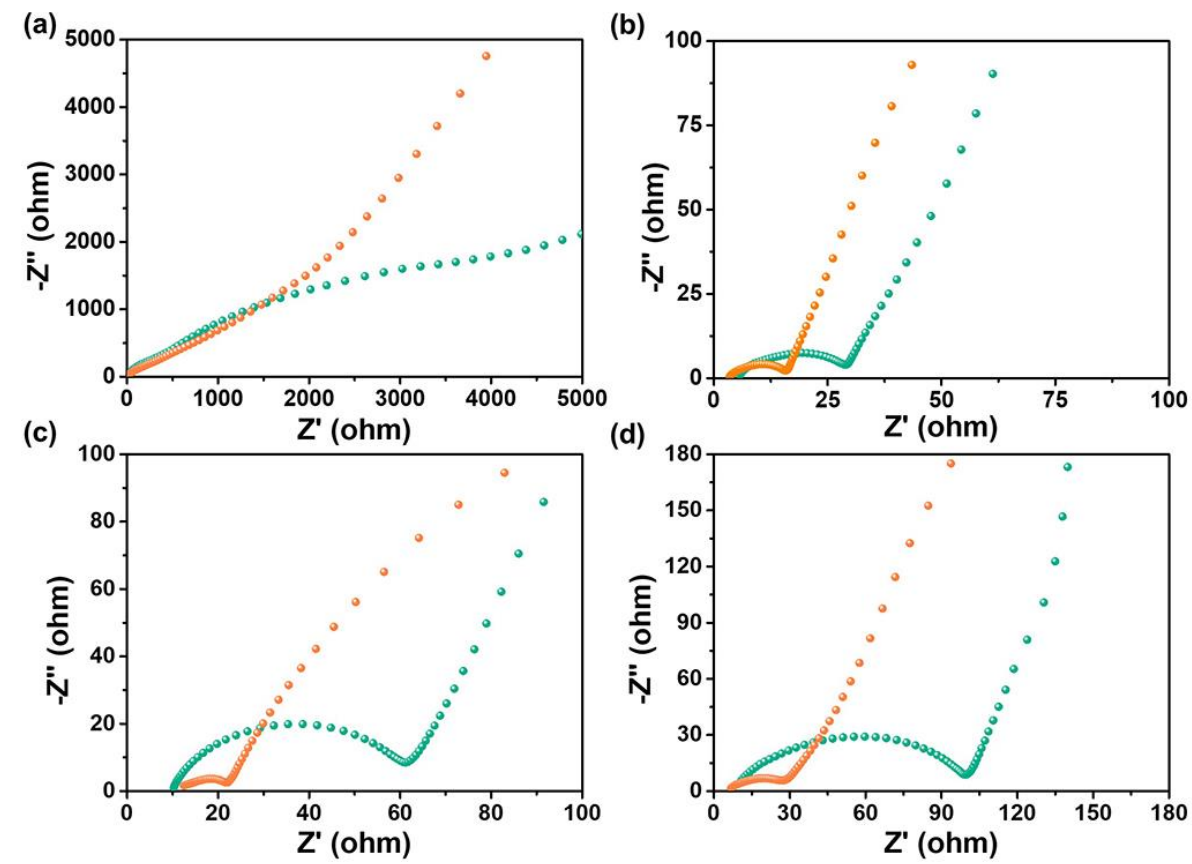

Figure S16. Nyquist plot of Li || $\mathrm{NCM}$ (Green) or $\mathrm{Cu} / \mathrm{Li}|| \mathrm{NCM}$ (Brown) full battery. (a)

Before cycling. (b) 5 cycle. (c) 50 cycle. (d) 100 cycle. 
(a)
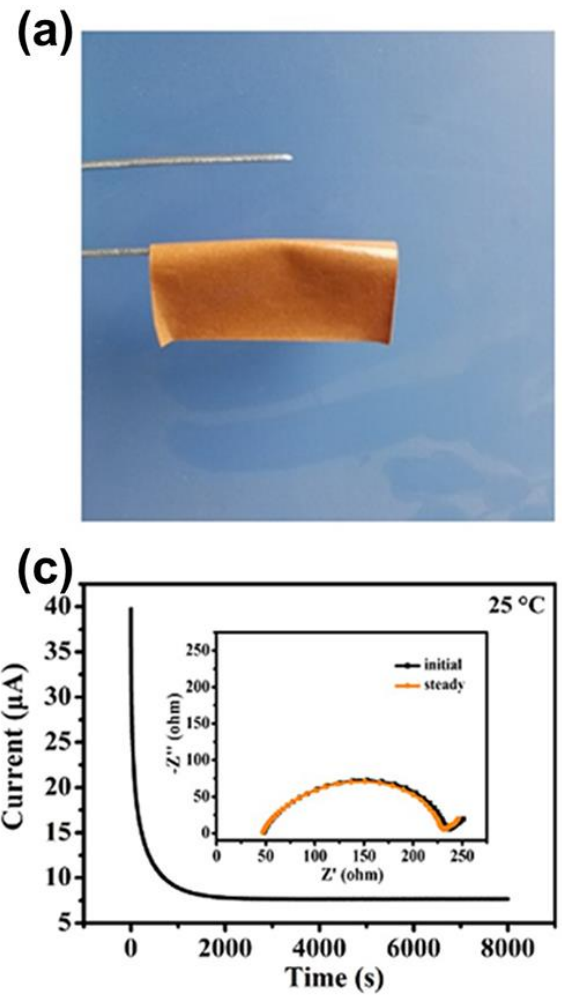

(b)

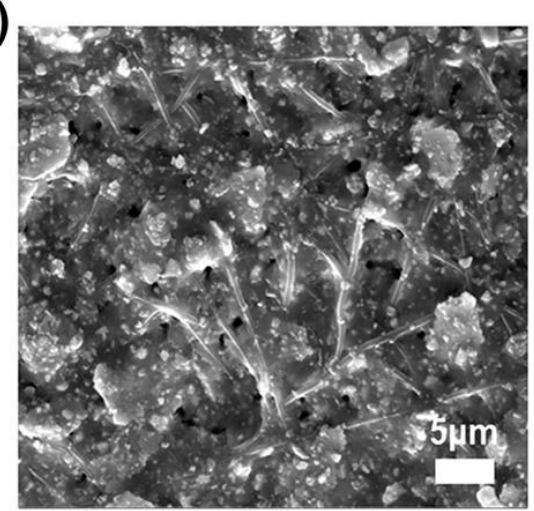

(d)

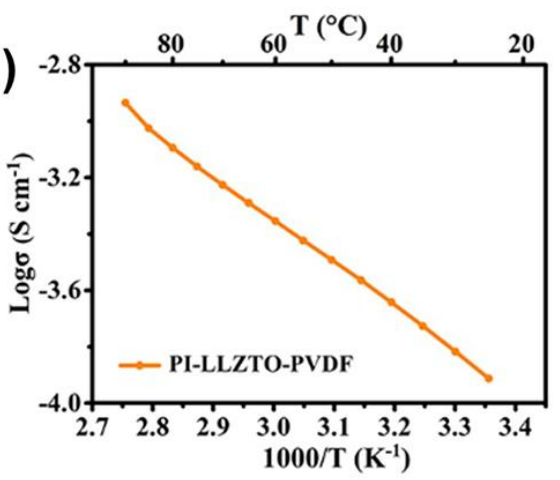

Figure S17. Characteristic of the composite PI-LLZTO-PVDF electrolyte. (a) Digital photos. (b) SEM image. (c) Current variation with time during polarization of a Li||PILLZTO-PVDF $\|$ Li symmetrical battery at $25^{\circ} \mathrm{C}$, with applying potential difference of $10 \mathrm{mV}$. Inset presents the AC impedance spectra of symmetrical battery. (d) Temperature dependence of ionic conductivities.

PVDF and LiTFSI were firstly dissolved in the NMP solution, and the LLZTO particles was introduced to the above solution. LLZTO and NMP can induce the alkaline-like reaction. La atoms in LLZTO can complex with $\mathrm{N}$ atoms and $\mathrm{C}=\mathrm{O}$ groups in NMP solvent molecules. Analogous to Lewis bases, this complex causes partial dehydrofluorination in the composite electrolyte and thus enhances the interactions between PVDF, LiTFSI and LLZTO particles, which is benefited to the improvement of ionic conductivity. ${ }^{[6]}$ The ionic conductivity of PI-LLZTO-PVDF electrolyte is $1.23 \times 10^{-4} \mathrm{~S} \mathrm{~cm}^{-1}$ at $25^{\circ} \mathrm{C}$ and the corresponding transference number is 0.51 . 

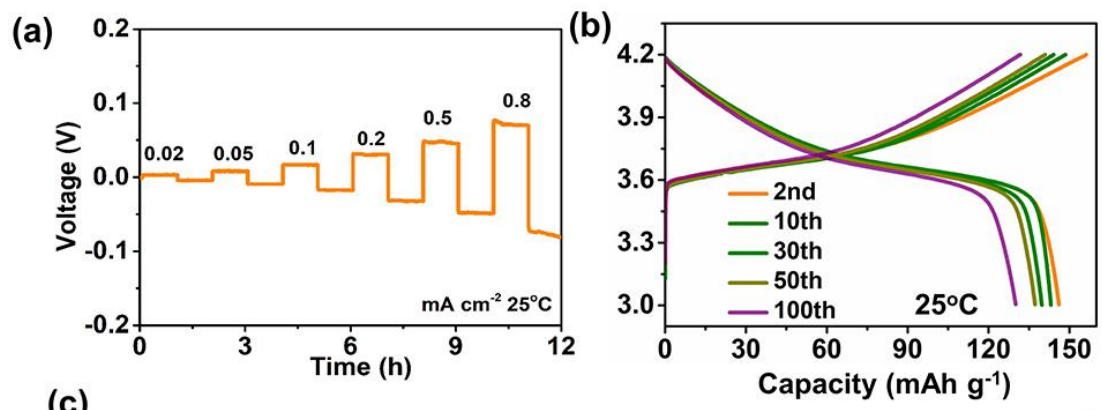

(c)

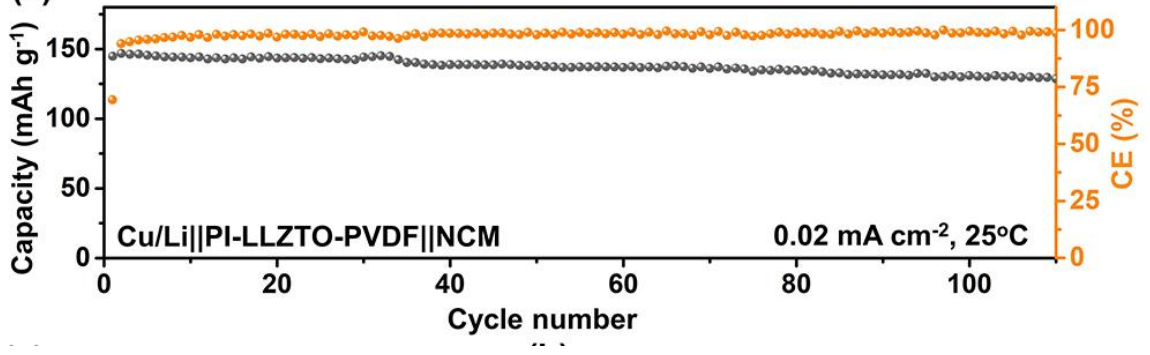

Figure S18 (a) Galvanostatic cycling of the $\mathrm{Cu} / \mathrm{Li}\|\mathrm{PI}-\mathrm{LLZTO}-\mathrm{PVDF}\| \mathrm{Cu} / \mathrm{Li}$ battery. (b) Typical charge-discharge voltage profiles and (c) Cycling stability of the $\mathrm{Cu} / \mathrm{Li} \| \mathrm{PI}-$ LLZTO-PVDF||NCM at $0.02 \mathrm{~mA} \mathrm{~cm}^{-2}$. 

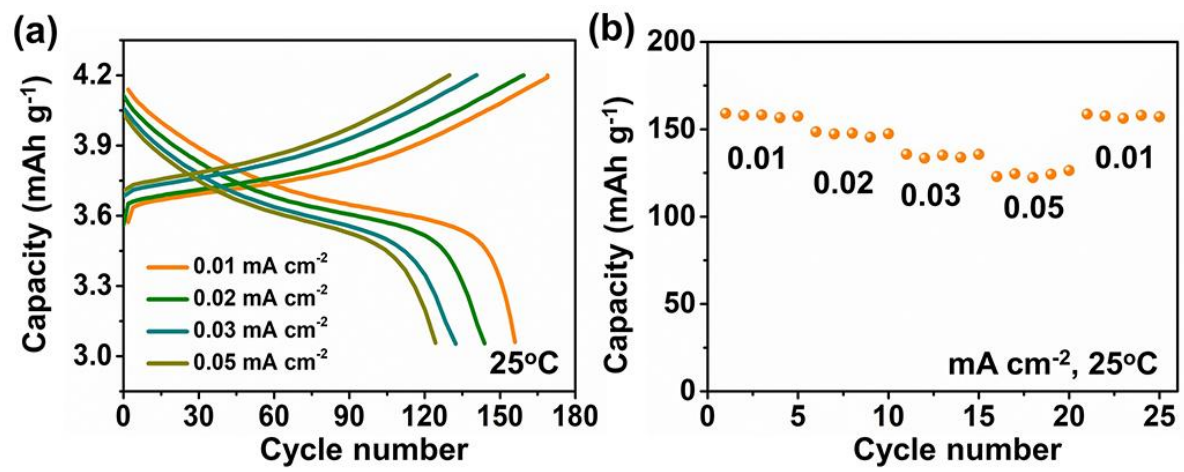

Figure S19. (a) Typical charge-discharge voltage at different state. (b) Rate capability.

The charge/discharge capacities of $\mathrm{Cu} / \mathrm{Li}\|\mathrm{PI}-\mathrm{LLZTO}-\mathrm{PVDF}\| \mathrm{NCM}$ battery at different rates of $0.01,0.02,0.03$, and $0.05 \mathrm{~mA} \mathrm{~cm}^{-2}$ exhibits high discharge capacities of $158.3,146.4,135.1$, and $124.2 \mathrm{mAh} \mathrm{g}^{-1}$, respectively. 


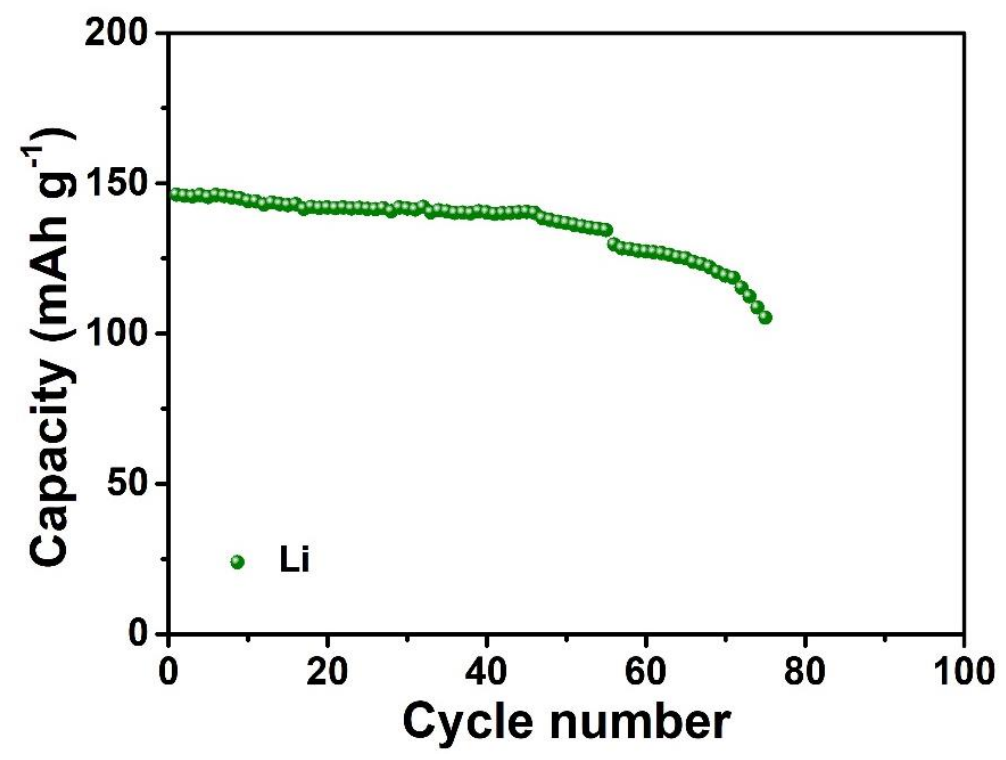

Figure S20 The cycle performance of Li|PI-LLZTO-PVDF|NCM battery. 


\section{Tables}

Table S1 Comparison in different aspects of varies reported composite Li anode by molten strategy.

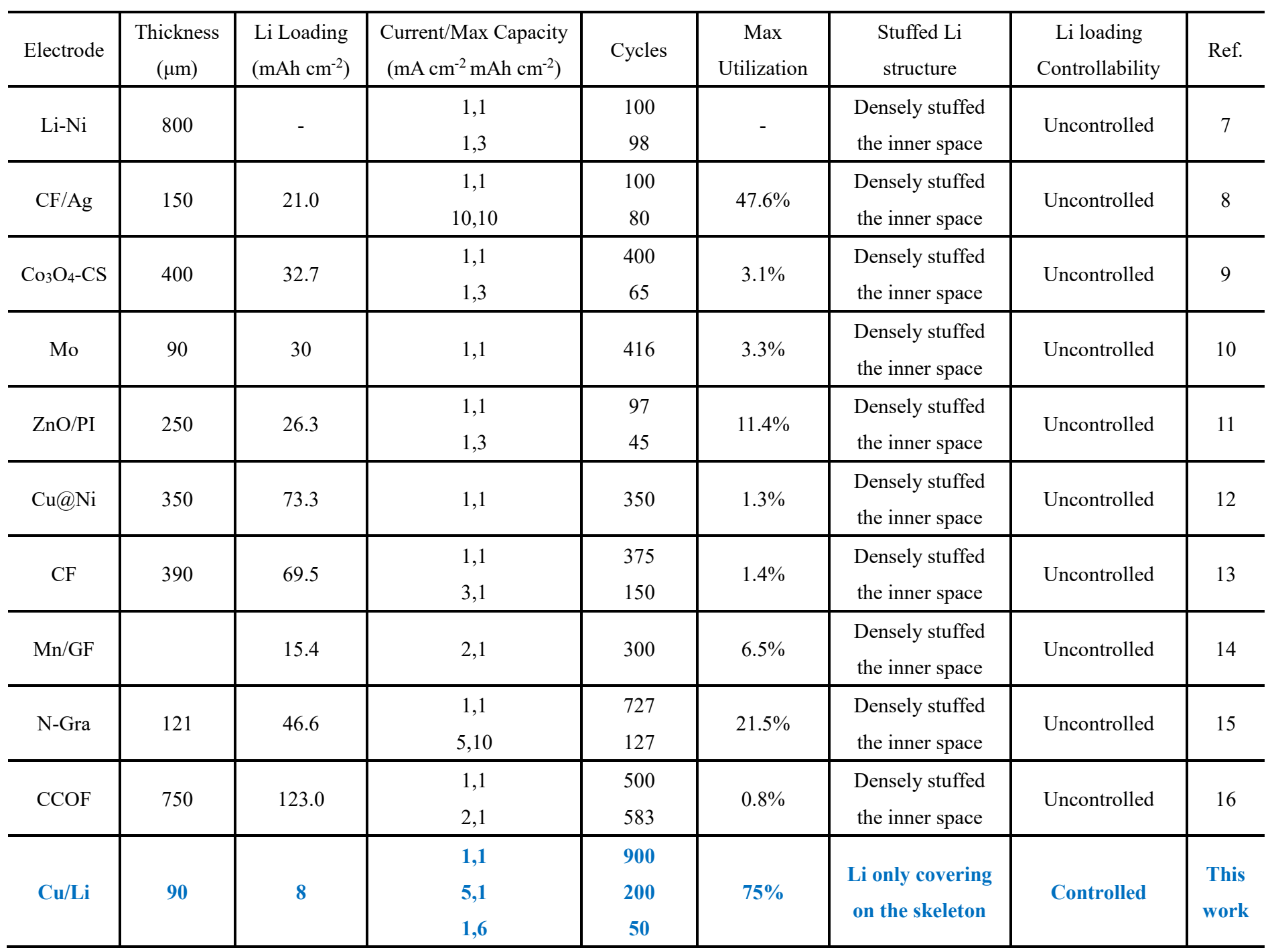

Note: Utilization: The max cycling capacity divided by the total mass that Li into the 3D frameworks.

Li-Ni: Presorting Li into nickel foam. Mo: Mo net. N-Gra: N-doped graphene. CCOF: A cupritecoated $\mathrm{Cu}$ foam. $\mathrm{ZnO} / \mathrm{PI}$ : $\mathrm{ZnO}$ coating on polyimide. $\mathrm{Cu} @ \mathrm{Ni}$ : $\mathrm{Ni}$ deposited on the $\mathrm{Cu}$ nanowires.

CF: Multilayer fibers with an alloy interlayer. $\mathrm{Co}_{3} \mathrm{O}_{4}$-CS: A hierarchical $\mathrm{Co}_{3} \mathrm{O}_{4}$ nanofiber-carbon sheet. $\mathrm{CF} / \mathrm{Ag}$ : Electroplating silver (Ag) particles onto coralloid carbon fiber. $\mathrm{MnO}_{2} / \mathrm{GF}$ : Graphene foams (GFs) decorated with the $\mathrm{MnO}_{2}$ nanoflakes. 



\section{Reference}

(1) Hu, J.; He, P.; Zhang, B.; Wang, B.; Fan, L.-Z., Porous film host-derived 3D composite polymer electrolyte for high-voltage solid state lithium batteries. Energy Storage Mater. 2020, 26, 283-289.

(2) Huang M.; Mao S.-J.; Shen Y. Nan C.-W.; Munakata H. Kanamura K., Preparation and electrochemical properties of $\mathrm{Zr}$-site substituted $\mathrm{Li}_{7} \mathrm{La}_{3}\left(\mathrm{Zr}_{2-\mathrm{x}} \mathrm{M}_{\mathrm{x}}\right) \mathrm{O}_{12}(\mathrm{M}=\mathrm{Ta}, \mathrm{Nb})$ solid electrolytes. J. Power Sources 2014, 261, 206-211.

(3) Wang, C.; Sun, Q.; Liu, Y.; Zhao, Y.; Li, X.; Lin, X.; Banis, M. N.; Li, M.; Li, W.; Adair, K. R.; Wang, D.; Liang, J.; Li, R.; Zhang, L.; Yang, R.; Lu, S.; Sun, X., Boosting the performance of lithium batteries with solid-liquid hybrid electrolytes: Interfacial properties and effects of liquid electrolytes. Nano Energy 2018, 48, 35-43.

(4) Wang Z.; Tan R.; Wang H. Yang L. Hu J. Chen H. Pan F., A Metal-OrganicFramework - Based Electrolyte with Nanowetted Interfaces for High-Energy-Density Solid-State Lithium Battery. Adv. Mater. 2018, 30, 1704436.

(5) Duan, H.; Fan, M.; Chen, W. P.; Li, J. Y.; Wang, P. F.; Wang, W. P.; Shi, J. L.; Yin, Y. X.; Wan, L. J.; Guo, Y. G., Extended Electrochemical Window of Solid Electrolytes via Heterogeneous Multilayered Structure for High-Voltage Lithium Metal Batteries. Adv. Mater. 2019, 31, 1807789.

(6) Zhang, X.; Liu, T.; Zhang, S.; Huang, X.; Xu, B.; Lin, Y.; Xu, B.; Li, L.; Nan, C. W.; Shen, Y., Synergistic Coupling between $\mathrm{Li}_{6.75} \mathrm{La}_{3} \mathrm{Zr}_{1.75} \mathrm{Ta}_{0.25} \mathrm{O}_{12}$ and Poly(vinylidene fluoride) Induces High Ionic Conductivity, Mechanical Strength, and 
Thermal Stability of Solid Composite Electrolytes. J. Am. Chem. Soc. 2017, 139, 13779-13785.

(7) Chi, S.-S.; Liu, Y.; Zhao, N.; Guo, X.; Nan, C.-W.; Fan, L.-Z., Solid polymer electrolyte soft interface layer with 3D lithium anode for all-solid-state lithium batteries. Energy Storage Mater. 2019, 17, 309-316.

(8) Zhang, R.; Chen, X.; Shen, X.; Zhang, X.-Q.; Chen, X.-R.; Cheng, X.-B.; Yan, C.; Zhao, C.-Z.; Zhang, Q., Coralloid Carbon Fiber-Based Composite Lithium Anode for Robust Lithium Metal Batteries. Joule 2018, 2, 764-778.

(9) Li, S.; Liu, Q.; Zhou, J.; Pan, T.; Gao, L.; Zhang, W.; Fan, L.; Lu, Y., Hierarchical $\mathrm{Co}_{3} \mathrm{O}_{4}$ Nanofiber-Carbon Sheet Skeleton with Superior Na/Li-Philic Property Enabling Highly Stable Alkali Metal Batteries. Adv. Funct. Mater. 2019, 29, 1808847.

(10) Yue, X. Y.; Li, X. L.; Bao, J.; Qiu, Q. Q.; Liu, T.; Chen, D.; Yuan, S. S.; Wu, X. J.; Lu, J.; Zhou, Y. N., “Top-Down” Li Deposition Pathway Enabled by an Asymmetric Design for Li Composite Electrode. Adv. Energy Mater. 2019, 9, 1901491. (11) Liu, Y.; Lin, D.; Liang, Z.; Zhao, J.; Yan, K.; Cui, Y., Lithium-coated polymeric matrix as a minimum volume-change and dendrite-free lithium metal anode. Nat. Commun. 2016, 7, 10992.

(12) Lu, L.-L.; Zhang, Y.; Pan, Z.; Yao, H.-B.; Zhou, F.; Yu, S.-H., Lithiophilic Cu-Ni core-shell nanowire network as a stable host for improving lithium anode performance. Energy Storage Mater. 2017, 9, 31-38. 
(13) Zhang, Y.; Wang, C.; Pastel, G.; Kuang, Y.; Xie, H.; Li, Y.; Liu, B.; Luo, W.; Chen, C.; Hu, L., 3D Wettable Framework for Dendrite-Free Alkali Metal Anodes. $A d v$. Energy Mater. 2018, 8, 1800635.

(14) Yu, B.; Tao, T.; Mateti, S.; Lu, S.; Chen, Y., Nanoflake Arrays of Lithiophilic Metal Oxides for the Ultra-Stable Anodes of Lithium-Metal Batteries. Adv. Funct. Mater. 2018, 28, 1803023.

(15) Huang, G.; Han, J.; Zhang, F.; Wang, Z.; Kashani, H.; Watanabe, K.; Chen, M., Lithiophilic 3D Nanoporous Nitrogen-Doped Graphene for Dendrite-Free and Ultrahigh-Rate Lithium-Metal Anodes. Adv. Mater. 2019, 31, e1805334.

(16) Yue, X.-Y.; Wang, W.-W.; Wang, Q.-C.; Meng, J.-K.; Wang, X.-X.; Song, Y.; Fu, Z.-W.; Wu, X.-J.; Zhou, Y.-N., Cuprite-coated Cu foam skeleton host enabling lateral growth of lithium dendrites for advanced Li metal batteries. Energy Storage Mater. 2019, 21, 180-189. 